\title{
Significance of cardiac murmurs in term neonates admitted to a neonatal intensive care unit of a tertiary level hospital in India
}

\author{
*Prashant Hari Bhadane ${ }^{1}$, Shakuntala Prabhu ${ }^{1}$, Sumitra Venkatesh ${ }^{1}$, Jayashree Mishra ${ }^{1}$
}

Sri Lanka Journal of Child Health, 2019; 48(1): 13-18

\begin{abstract}
Introduction: There is a paucity in the literature of prospective studies on neonatal heart murmurs and their correlation with the diagnostic yield on $2 \mathrm{D}$ echocardiography.
\end{abstract}

Objectives: To assess the prevalence of cardiac murmurs in neonates and their significance using 2D Echocardiography/Colour Doppler.

Method: A prospective descriptive analytical study was carried out on 100 term neonates admitted to the neonatal intensive care unit (NICU) of a tertiary level hospital from April - November 2017 with audible systolic (grade $2 / 6$ or above), diastolic ( $2 / 4$ or above) or continuous murmurs. These patients were evaluated with a detailed 2D Echocardiogram /Colour Doppler on portable Sonosite / Epiq using an $8-12 \mathrm{~Hz}$ probe. Patient with isolated small patent foramen ovale $(<5 \mathrm{~mm})$ and those admitted to the NICU with diagnosed cardiac disease were excluded from study. A 100 term neonates without murmur were used as controls. The results obtained were statistically analysed using SPSS software. $p$ $<0.05$ was taken as significant Institutional Ethics Committee approval was obtained prior to study.

Results: Of the 100 neonates with murmur, 65 $(65 \%)$ had significant structural defects and 35 $(35 \%)$ had no structural heart defects. The mean hospital stay was 13.03 days. Seventy five (75\%) neonates had good outcome and 25 (25\%) had poor outcome in the form of prolonged NICU stay and mortality. Of the 100 neonates without murmur, 97 (97\%) had good outcome and 3 (3\%) had poor outcome due to non-cardiac issues.

Conclusions: The prevalence of murmurs among neonates was 6.2 per 1,000 live births in inborn

\footnotetext{
$\overline{{ }^{1} \text { Department of Paediatric Cardiology, B J Wadia }}$ Hospital for Children, Mumbai, Maharashtra, India

*Correspondence: drprashantbhadane@gmail.com (Received on 04 March 2018: Accepted after revision on 20 April 2018)

The authors declare that there are no conflicts of interest

Personal funding was used for the project.

Open Access Article published under the Creative
}

Commons Attribution CC-BY (C) () deliveries (excluding previously diagnosed cases). Complex structural abnormalities were found in $28 \%$ of neonates with murmurs. The rest had isolated lesions or single structural lesions such as VSD (19\%), PDA (18\%) or ASD (2\%).

DOI: http://dx.doi.org/10.4038/sljch.v48i1.8646

(Key words: Congenital heart disease, cardiac murmur, neonate)

\section{Introduction}

Congenital heart disease (CHD) has an incidence of around $0.8-1$ per 1000 live births globally ${ }^{1,2}$. Early detection will improve management and outcome ${ }^{3}$. Ultrasound scanning during pregnancy and postnatal clinical examination have a low rate of CHD detection ${ }^{4,5,6}$. Routine clinical examination diagnoses less than $50 \%$ of the children with $\mathrm{CHD}^{5}$. Electrocardiography (ECG) and chest $\mathrm{x}$-ray contribute little to diagnosis of heart murmurs ${ }^{7,8,9}$. Murmur is the commonest reason for cardiac consultation ${ }^{10}$. Echocardiography should complement clinical diagnosis if easily available, to avoid missing life threatening cardiac lesions ${ }^{11,12}$. Paucity in the literature of prospective studies on neonatal heart murmurs and their correlation with diagnostic yield on echocardiography, prompted us to undertake this study.

\section{Objectives}

To assess the prevalence of cardiac murmurs and their significance in babies admitted to a neonatal intensive care unit (NICU) compared to a control group of term neonates without cardiac murmurs using 2D Echocardiography/ Colour Doppler.

\section{Method}

A prospective descriptive analytical study was carried out on 100 neonates with varied diagnoses admitted to the 150 bedded neonatal intensive care unit (NICU) of a tertiary level hospital. Institutional Ethics Committee approval was obtained prior to the study. NICU setting has both intramural and extramural services. All full term neonates in whom cardiac murmurs were detected on routine examination were included in the study. Babies with audible murmurs were assessed with a detailed 2D Echocardiogram/Colour Doppler on portable Sonosite / Epiq using an 8-12 Hz probe. Neonates included in study were those with audible, systolic (grade 2/6 or above) and diastolic 
(grade $2 / 4$ or above) murmurs heard by fellow or consultant and confirmed by cardiologist or continuous murmurs detected by NICU. Study period was 8 months from April - November 2017. Full term ( $>37$ weeks) neonates with murmurs were included and infants with previously documented or suspected CHD on fetal echocardiogram, Patient with isolated small patent foramen ovale $(<5 \mathrm{~mm})$ and those admitted in NICU with diagnosed cardiac disease were excluded from the study. One hundred full term neonates without murmurs were taken as controls. Murmur, for study purposes was defined as audible systolic murmur ( $\geq$ grade $2 / 6$ ), diastolic ( $\geq$ grade 2/4) and continuous murmur.

Case record form for the study was designed and included age at presentation, gender, address, family history, antenatal history, gestational age, birth weight, heart rate (HR), respiratory rate (RR), saturation (SPO2), clinical examination details including findings on general examination, cardiac examination, comorbid findings, cyanosis, chest $\mathrm{x}$ ray (if available) and $2 \mathrm{D}$ echocardiogram findings.
Based on echocardiographic data neonates were divided into those with innocent and pathological murmurs. Number of days of hospitalisation and outcome were noted. The course of the neonate in hospital and the diagnosis on discharge were also noted. If the child needed intervention or surgery for cardiac condition it was recorded. The outcomes were classified as favourable/good in the form of early recovery and brief NICU stay from the cardiac point of view and not favourable/poor in the form of prolonged NICU stay or mortality.

Statistical analysis: The results obtained were statistically analysed by Chi square test and graphically displayed. $p<0.05$ was taken as significant. All statistical analyses were performed using SPSS software version 23.

The guideline for cardiac murmur identified at newborn examination is shown in Figure 1.

\section{Guideline for cardiac murmur identified at newborn examination}

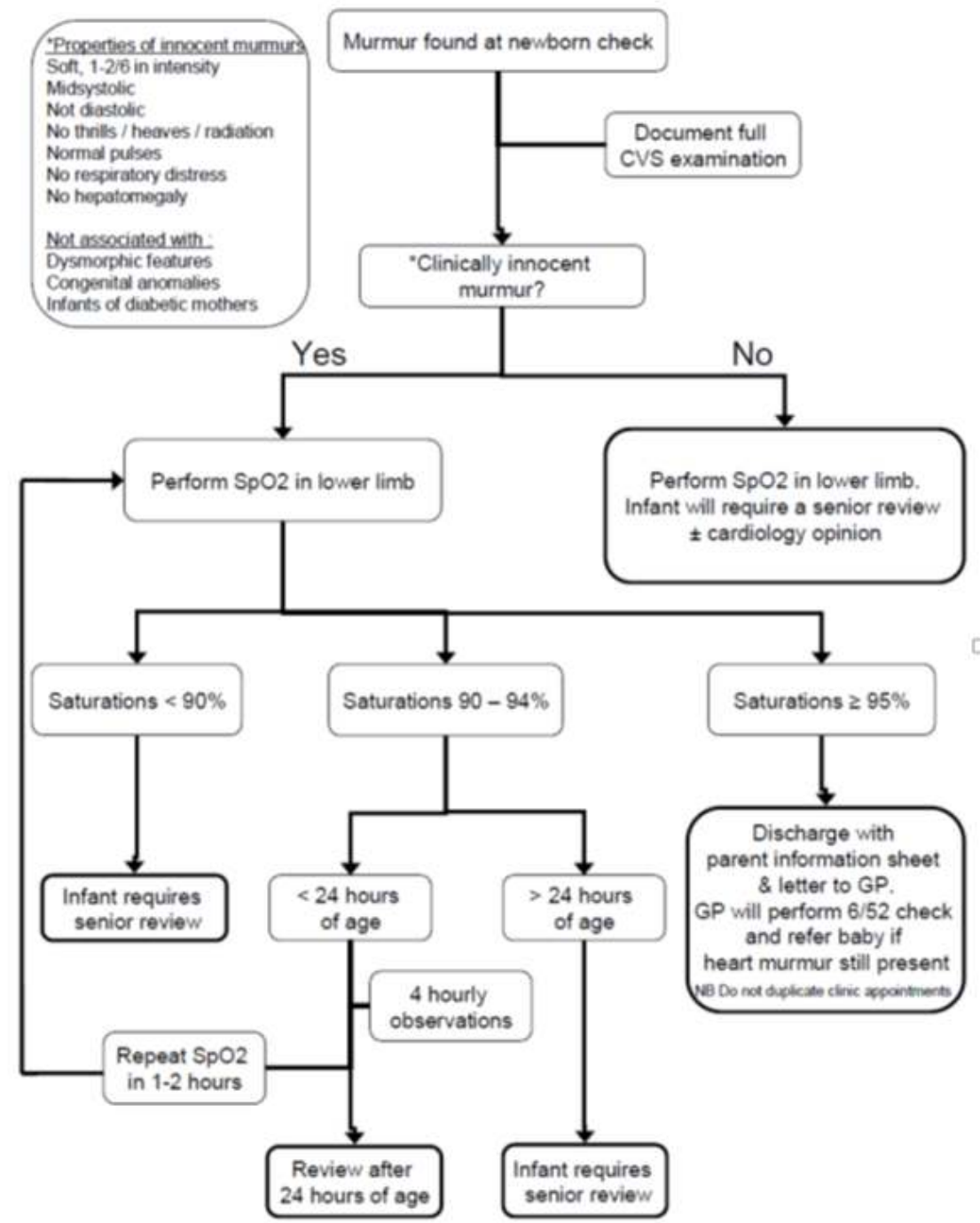

Figure 1: Guideline for cardiac murmur identified at newborn examination 


\section{Results}

There were 3903 live births recorded during the eight month period. Of them, 100 neonates had audible murmurs. Of the 100 neonates, $66 \%$ presented between 0 to 10 days of life, $22 \%$ between 11 to 20 days of life, and $12 \%$ between 21 to 28 days of life. The mean age of presentation of murmur in our study was 8.4 days. Among the inborn babies, the prevalence of murmurs, in babies previously not known to have congenital heart disease, was 6.2 per 1,000 live births. Incidence of murmurs was 39.2 per 1,000 live births in the outborn, identified through precordial auscultation. The outborn babies were excluded from prevalence calculation as birth prevalence could not be estimated. The male: female ratio of the 100 neonates with murmur was 1.22:1. The mean maternal age was 24.5 years, ranging from 18 to 42 years. The mean heart rate was 133 beats per minute.
On clinical examination, $68 \%$ neonates had ejection systolic murmur, $3 \%$ had continuous murmur and $29 \%$ had pansystolic murmur. The intensity of the murmur was not related to the presence or absence of CHD. The mean percentage oxygen saturation was $96.7 \%, 83 \%$ having saturations between $95-100 \%, 6 \%$ between 90 $94 \%, \quad 8 \%$ between $85-89 \%$ and $3 \%$ having saturations less than $85 \%$. Neonates with cyanosis were $13 \%$ and neonates without cyanosis were $87 \%$. Among the 100 neonates with murmur, the common lesions found on echocardiography were ventricular septal defect $(19 \%)$, patent ductus arteriosus (18\%), atrial septal defect $(2 \%)$ and cyanotic heart with multiple structural lesions (28\%). Anatomic lesions diagnosed on 2 D echocardiography/Colour Doppler in neonates with murmur are shown in Table 1

Table 1: Anatomic lesions diagnosed on 2 D echocardiography/Colour Doppler in neonates with murmur

\begin{tabular}{|l|c|}
\hline \multicolumn{1}{|c|}{ Type of lesion } & $\begin{array}{c}\text { No. of } \\
\text { neonates }\end{array}$ \\
\hline Peripheral branch pulmonary artery stenosis & 35 \\
\hline Ventricular septal defect (VSD) & 19 \\
\hline Patent ductus arteriosus (PDA) & 18 \\
\hline Transposition of the great arteries (TGA) + VSD + PDA & 4 \\
\hline VSD + atrial septal defect (ASD) & 2 \\
\hline Double outlet right ventricle (DORV) + single ventricle (SV) + large ASD & 2 \\
\hline DORV + VSD + pulmonary stenosis (PS) & 2 \\
\hline Hypoplastic left heart syndrome (HLHS) & 2 \\
\hline Coarctation of aorta (COA) + ASD & 2 \\
\hline Tetralogy of Fallot (TOF) + pulmonary atresia + large PDA & 2 \\
\hline Ostium secundum ASD + PDA & 1 \\
\hline VSD + COA & 1 \\
\hline TGA + intact ventricular system (IVS) + PDA & 1 \\
\hline Ebstein anomaly & 1 \\
\hline Dysplastic tricuspid valve (TV) +Severe tricuspid regurgitation (TR) & 1 \\
\hline Dysplastic TV + tiny PDA & 1 \\
\hline Coronary sinus (CS) Total anomalous pulmonary venous connection (TAPVC) + small VSD & 1 \\
\hline CS TAPVC + small ASD & 1 \\
\hline Tricuspid atresia (TA) + large PDA & 1 \\
\hline Pulmonary atresia + IVS + PDA & 1 \\
\hline Partial anomalous pulmonary venous connection (PAPVC) + VSD + PDA & 1 \\
\hline Complex = Complete atrioventricular canal defect (CAVCD) + DORV + TGA + TAPVC. & 1 \\
\hline Total & 100 \\
\hline
\end{tabular}

Anatomic lesions diagnosed on 2D echocardiography/ Colour Doppler in neonates without murmur are shown in Table 2

Figure 2 shows the classification of murmurs after 2D echocardiography.
Table 2

Anatomic lesions diagnosed on 2D echocardiography / Colour Doppler in neonates without murmur $(n=100)$

\begin{tabular}{|l|c|}
\hline \multicolumn{1}{|c|}{ Type of lesion } & Number \\
\hline Normal & 71 \\
\hline Patent ductus arteriosus (PDA) & 10 \\
\hline Patent foramen ovale (PFO) & 13 \\
\hline PFO + PDA & 6 \\
\hline
\end{tabular}




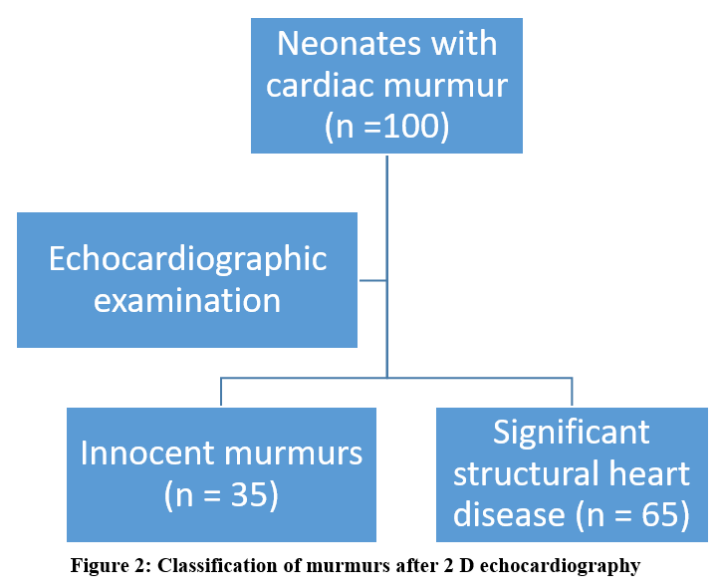

Of the 100 neonates, $65 \%$ had significant structural defects (Figure 3). Of the 65\%, 11\% were duct dependent lesions needing change of routine care. Ventricular septal defect (VSD) was diagnosed in $19 \%$. Most VSDs were small and in the perimembranous and muscular portion of the interventricular septum.

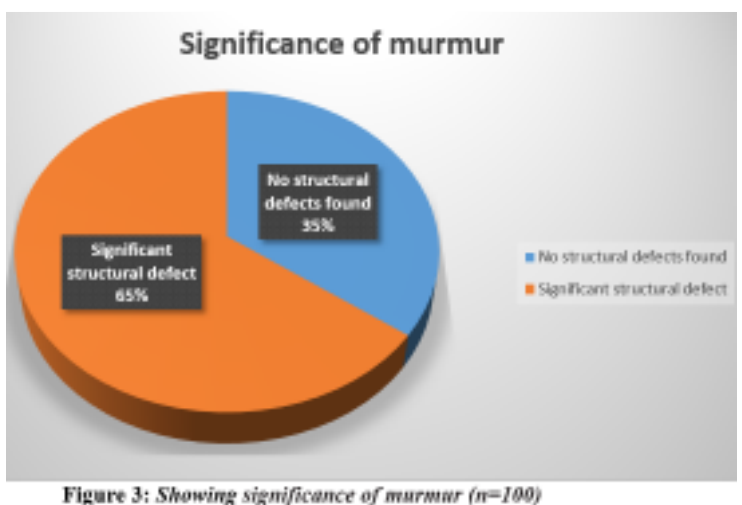

Of the 100 neonates with murmur, $48 \%$ were hospitalised between day 1 to day $10,37 \%$ between day 11 to day $20,14 \%$ between day 21 to day 30 and $01 \%$ was hospitalised more than 30 days (Figure 4). The mean hospital stay was 13.03 days.

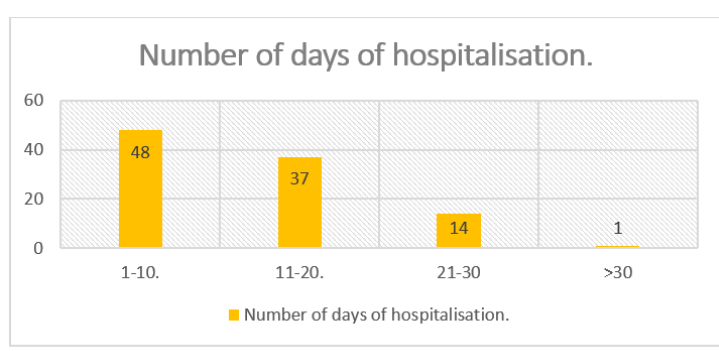

Figure 4: Showing number of days of hospitalisation of neonates with murmur

Of the 100 neonates without murmur, $81 \%$ were hospitalised between day 1 to day $10,15 \%$ between day 11 to day $20,04 \%$ between day 21 to day 30 and none were hospitalised more than 30 days. Of the 100 neonates with murmur, $75 \%$ had good outcome and $25 \%$ had poor outcome in the form prolonged NICU stay and mortality (Table 3 ).

Table 3: Outcome

\begin{tabular}{|l|c|c|c|}
\hline \multicolumn{1}{|c|}{ Outcome } & $\begin{array}{c}\text { Neonates with murmur } \\
\text { Number (\%) }\end{array}$ & $\begin{array}{c}\text { Neonates without murmur } \\
\text { Number (\%) }\end{array}$ & $\boldsymbol{p}$ value \\
\hline Good & $75(75)$ & $97(97)$ & 0.000007 \\
\cline { 1 - 3 } Bad & $25(25)$ & $03(03)$ & \\
\hline Total & $100(100)$ & $100(100)$ & \\
\hline
\end{tabular}

Comorbid conditions noted in neonates with murmur were anorectal malformation, sepsis, arterio-venous (AV) malformation, congenital diaphragmatic hernia and tracheoesophageal fistula. Of the 100 neonates without murmur, 97 (97\%) had good outcome and $3(3 \%)$ had bad outcome due to non-cardiac issues. $\mathrm{P}$ value is significant ( $p=0.000007)$. Simple congenital heart diseases like VSD, atrial septal defect (ASD) and patent ductus arteriosus (PDA) were managed on medical follow up. Complex congenital heart disease required interventions in the form of palliative or corrective surgery.

\section{Discussion}

CHD is still an important cause of morbidity and mortality $^{13}$. Neonatal heart murmur is the commonest cause of cardiologist consultation in neonatal intensive care units and nurseries ${ }^{14}$. Prevalence of heart murmur in neonates varies from 6-770 per 1000 live births ${ }^{11,15}$. In present study the prevalence of murmurs was 6.2 per 1,000 live births in inborn. This prevalence is low as antenatally diagnosed cases were not included. The outborn babies were excluded from prevalence calculation as birth prevalence could not be estimated. 
On clinical examination of 100 neonates with murmur, $68 \%$ had ejection systolic murmur, $3 \%$ had continuous murmur and $29 \%$ had pansystolic murmur. The intensity of the murmur was not related to the presence or absence of CHD. The mean percentage oxygen saturation was $96.7 \%$. Whilst $13 \%$ neonates had cyanosis, $87 \%$ were without cyanosis. Thus, in this study, acyanotic heart disease was more prevalent than cyanotic heart disease. A study by Tanner et al found benign murmurs in $48.4 \%$ and structural cardiac defects in $51.6 \%$ neonates $^{16}$. If a heart murmur is audible, the probability of an underlying cardiac anomaly is $65 \%{ }^{17,18}$. In our study $65 \%$ of neonates with heart murmur had underlying structural cardiac malformations, $19 \%$ being VSDs alone and $11 \%$ being duct dependent lesions needing change of routine care. Most VSDs were small and in the perimembranous and muscular portion of the interventricular septum. Studies using echoDoppler cardiography have demonstrated a high prevalence of muscular VSDs in neonates ${ }^{19}$.

Clinical examination of the neonate can detect only $44-45 \%$ of cardiac anomalies presenting in infants ${ }^{11,20,21}$. Our study was limited to live born neonates and focused on the clinical significance of precordial murmurs heard during the routine neonatal examination. Among the 100 neonates with murmur, the common lesions found on echocardiography were VSD (19\%), PDA (18\%), ASD $(2 \%)$ and cyanotic heart with multiple structural lesions $(28 \%)$.

With respect to outcome, $75 \%$ of neonates had good outcome and $25 \%$ had poor outcome in the form prolonged NICU stay more than 30 days and mortality. Comorbid conditions noted in neonates with murmur were anorectal malformation, sepsis, AV malformation, congenital diaphragmatic hernia and tracheoesophageal fistula which added to the mortality and prolonged morbidity. Neonates with duct dependent circulation needed urgent attention and were referred for intervention or surgery depending upon the clinical scenario, indicating that early detection and diagnosis helps to offer better care and timely interventions. Hence innocent murmurs are only innocent after echocardiographic diagnosis. Most of these patients with neonatal murmurs were asymptomatic and majority of these defects were small and closed spontaneously.

\section{Conclusions}

The prevalence of murmurs among neonates was 6.2 per 1,000 live births in inborn deliveries (excluding previously diagnosed cases). Complex structural abnormalities were found in $28 \%$ of neonates with murmurs. The rest had isolated lesions or single structural lesion and the most common single lesions were VSD (19\%), PDA $(18 \%)$, and ASD (2\%).

\section{References}

1. Botto LD, Correa A, Erricson JD. Racial and temporal violations in the prevalence of heart defects. Pediatrics 2001; 107(3): E32.

https://doi.org/10.1542/peds.107.3.e32

PMid: 11230613

2. Talner CN. Report of the New England Regional Infant Cardiace Program by Donald C Fyler, MD. Pediatrics 1980; 65: 375-461. Pediatrics 1998; 102(1 pt 2): 258-9.

PMid: 9651450

3. Brown KL, Ridout DA, Hoskote A, Verhulst L, Ricci M, Bull C. Delayed diagnosis of congenital heart disease worsens preoperative condition and outcome of surgery in neonates. Heart 2006; 92: 298-302.

https://doi.org/10.1136/hrt.2005.078097

PMid: 16449514 PMCid: PMC1861169

4. Abu-Harb M, Wyllie J, Hey E, Richmond S, Wren C. Presentation of obstructive left heart malformations in infancy. Archives of Disease in Childhood 1994; 71: F179F183.

https://doi.org/10.1136/fn.71.3.F179

5. Wren C, Richmond S, Donaldson L. Presentation of congenital heart disease in infancy: implications for routine examination. Archives of Disease in Childhood Fetal and Neonatal Edition 1999; 80: F49-F53. https://doi.org/10.1136/fn.80.1.F49 PMid: 10325813 PMCid: PMC1720871

6. Bull $\mathrm{C}$ for the British Paediatric Cardiac Association. Current and potential impact of fetal diagnosis on prevalence and spectrum of serious congenital heart disease at term in the UK. Lancet 1999; 354: 1242-7.

https://doi.org/10.1016/S01406736(99)011 67-8

7. Danford DA. Effective use of the consultant, laboratory testing, and echocardiography for the paediatric patient with heart murmur. Pediatric Annals 2000; 29(8): 482-8. 
https://doi.org/10.3928/0090-4481-

20000801-07

PMid: 10960950

8. Poddar B, Basu S. Approach to a child with a heart murmur. Indian Journal of Pediatrics 2004; 71(1): 63-66. https://doi.org/10.1007/BF02725659 PMid: 14979389

9. Yi MS, Kimball TR, Tsevat J, Mrus JM, Kotagal UR. Evaluation of heart murmurs in children: cost-effectiveness and practical implications. Journal of Pediatrics 2002; 141(4): 504-11. https://doi.org/10.1067/mpd.2002.127502 PMid: 12378189

10. Pelech AN. Evaluation of the pediatric patient with a cardiac murmur. Pediatric Clinjes of North America 1999; 46(2): 167-88. https://doi.org/10.1016/S00313955(05)701 $11-5$

11. Ainsworth S, Wyllie JP, Wren C. Prevalence and clinical significance of cardiac murmurs in neonates. Archives of Disease in Childhood Fetal and Neonatal Edition 1999; 80(1): F43-F45. https://doi.org/10.1136/fn.80.1.F43 PMid: 10325811 PMCid: PMC1720873

12. Azhar AS, Habib HS. Accuracy of the initial evaluation of heart murmurs in neonates: do we need an echocardiogram? Pediatric Cardiology 2006; 27(2): 234-7. https://doi.org/10.1007/s00246-005-11221

PMid: 16391989

13. Rosenthal G. Prevalence of congenital heart disease. In: Garson A, Bricker JT, Fisher DJ, Neish SR, editors. The Science and Practice of Pediatric Cardiology. 2nd ed. Vol. 2. Pennsylvania: Williams \& Wilkins Co; 1998. pp. 1083-105.

14. Geggel RL. Conditions leading to paediatric cardiology consultation in a tertiary academic hospital. Pediatrics 2004; 114(4):e409-17.

https://doi.org/10.1542/peds.2003-0898-L

PMid: 15466065
15. Takami T, Kawashima H, Kamikawa A, Nemoto S, Takei Y, Miyajima T, Hoshika A. Prevalence of cardiac murmur detected on routine neonatal examination. Journal of Tokyo Medical University 2001; 59(4):290-3.

16. Tanner K, Sabrine N, Wren C. Cardiovascular malformations among preterm infants. Pediatrics 2005; 116(6):e833-8. https://doi.org/10.1542/peds.2005-0397 PMid: 16322141

17. Wu $\mathrm{MH}$, Chen $\mathrm{HC}$, $\mathrm{Lu} \mathrm{CW}$, et al. Prevalence of congenital heart disease at live birth in Taiwan. Journal of Pediatrics 2010; 156(5):782-5. https://doi.org/10.1016/j.jpeds.2009.11.06 2

PMid: 20138303

18. Du ZD, Roguin N, Barak M. Clinical and echocardiographic evaluation of neonates with heart mumurs. Acta Paediatrica 1997; 86(7):752-6.

https://doi.org/10.1111/j.16512227.1997.t b08580.x

19. Hiraishi S., Agata Y., Nowatari M., Oguchi K., Misawa H., Hirota H. Incidence and natural course of trabecular ventricular septal defect: two dimensional echocardiography and colour Doppler flow imaging study. Journal of Pediatrics 1992; 120:409-15.

https://doi.org/10.1016/S00223476(05)809 06-0

20. Wren C, Richmond S, Donaldson L. Presentation of congenital heart disease in infancy: implications for routine examination. Archives of Disease in Childhood Fetal and Neonatal Edition 1999; 80(1): F49-F53.

https://doi.org/10.1136/fn.80.1.F49

PMid: 10325813 PMCid: PMC1720871

21. Hossain MM, Hasan MN, Shirin M, Mamun MA, Hossain MDD. Bangladesh Journal of Child Health 2010; 34(2): 5661. 